\title{
Pregnancy and Breast Cancer: when They Collide
}

\author{
Traci R. Lyons • Pepper J. Schedin • Virginia F. Borges
}

Received: 31 March 2009/Accepted: 3 April 2009 /Published online: 21 April 2009

(C) The Author(s) 2009. This article is published with open access at Springerlink.com

\begin{abstract}
Women of childbearing age experience an increased breast cancer risk associated with a completed pregnancy. For younger women, this increase in breast cancer risk is transient and within a decade after parturition a cross over effect results in an ultimate protective benefit. The post-partum peak of increased risk is greater in women with advanced maternal age. Further, their lifetime risk for developing breast cancer remains elevated for many years, with the cross over to protection occurring decades later or not at all. Breast cancers diagnosed during pregnancy and within a number of years post-partum are termed pregnancy-associated or PABC. Contrary to popular belief, PABC is not a rare disease and could affect up to 40,000 women in 2009. The collision between pregnancy and breast cancer puts women in a fear-invoking paradox of their own health, their pregnancy, and the outcomes for both. We propose two distinct subtypes of PABC: breast
\end{abstract}

T. R. Lyons · P. J. Schedin · V. F. Borges

Department of Medicine, Division of Medical Oncology,

University of Colorado Denver,

Aurora, CO, USA

P. J. Schedin · V. F. Borges

University of Colorado Cancer Center,

University of Colorado Denver,

Aurora, CO, USA

P. J. Schedin

AMC Cancer Research Center, University of Colorado Denver, Aurora, CO, USA

V. F. Borges $(\bowtie)$

Division of Medical Oncology, University of Colorado Denver,

Mail Stop 8117, RC-1 S, 12801 E. 17th Avenue, UCD,

Aurora, CO 80045, USA

e-mail: virginia.borges@ucdenver.edu cancer diagnosed during pregnancy and breast cancer diagnosed post-partum. This distinction is important because emerging epidemiologic data highlights worsened outcomes specific to post-partum cases. We reported that post-partum breast involution may be responsible for the increased metastatic potential of post-partum PABC. Increased awareness and detection, rationally aggressive treatment, and enhanced understanding of the mechanisms are imperative steps toward improving the prognosis for $\mathrm{PABC}$. If we determine the mechanisms by which involution promotes metastasis of $\mathrm{PABC}$, the post-partum period can be a window of opportunity for intervention strategies.

Keywords Pregnancy B Breast cancer- Involution ·

Metastasis
Abbreviations
PABC Pregnancy associated breast cancer
BRCA1 Breast cancer type 1 susceptibility protein
BRCA2 Breast cancer type 2 susceptibility protein
IGF-1 Insulin like growth factor 1
ECM Extracellular matrix
BMI Body mass index
MMP Matrix metalloproteinase

The interactions between pregnancy and breast cancer are complex and variable. More often than is frequently realized, these interactions are negative with regard to the resultant outcomes. The influence of pregnancy on the risk of developing breast cancer is dependent on maternal features, including age, family history, lactation postpartum, and overall parity. The risk for future breast cancer after a pregnancy follows a pattern curve of increased then decreased risk over time, with the zenith and subsequent 
nadir of the curve impacted by the afore mentioned criteria. Even more complex, perhaps, is the interaction of breast cancer cases with concomitant pregnancy or cases diagnosed closely thereafter. The increased incidence and metastatic potential from these tumors has been well outlined in epidemiologic research with the search for mechanisms ongoing. We will review the known interactions of pregnancy and breast cancer for both the effect of pregnancy on incidence and prognosis of the disease. Epidemiologic evidence, data on identified and potential mechanisms underpinning these events, and our hypotheses as to the role of involution in these events will be discussed.

\section{Epidemiology of Pregnancy and Breast Cancer Incidence: the Dual and Cross-over Effects}

Completion of a pregnancy invokes two potentially opposing effects on the mother's subsequent risk of breast cancer, hence the dual effect of pregnancy. Most familiar in breast cancer risk tables is the association of parity with a lifetime reduction in breast cancer risk. However, studies of breast cancer incidence in young women demonstrate a clinically underrecognized transient increase in breast cancer risk in the years immediately following pregnancy where all parous women, regardless of age, have higher incidence of breast cancer compared with nulliparous women [1-4]. This increase in risk has been shown to persist for at least ten [2, 3] and up to 15 years after birth in women under age 25 at delivery [1]. Unfortunately, delayed childbearing further increases this transient risk for subsequent breast cancer, with maternal age greater than 30 at first birth resulting in both an elevation of the peak incidence in the initial years post-partum and a longer tail effect of increased risk persisting for 30-50 years post-partum [1-5].

Evolving epidemiologic research demonstrates differences in incidence risk during this post-partum transient peak, dependent upon which additional variables are analyzed. In addition to maternal age, total number of pregnancies and family history are important contributors to the risk effect of pregnancy on breast cancer incidence. In one study of uni-parous women, the transient increase in risk peaked at 5 years after first delivery and leveled off 15 years after delivery [4]. Women who were bi-parous, regardless of age at second birth, had a lower magnitude of transient increase in risk [1] that also peaked earlier, at 3 years post-partum [4]. This alteration in risk profile is possibly due to an overlap, or stacking, of effects conferred by their first pregnancy. The transient increase in breast cancer incidence following childbirth is worsened by a concomitant family history of breast cancer [6]. Moreover, advanced maternal age and family history act synergistically to increase risk. Women 30 years of age or older at first birth with a family history have a three-fold increased risk over those with no family history, and this risk persists longer, for 20-30 years post-partum [5, 6]. Furthermore, women with germline mutations in the breast cancer susceptibility genes BRCA1 or BRCA2 experience a similar transient increase in breast cancer incidence compared to their high risk, nulliparous controls [7, 8].

Though the initial effect of any completed pregnancy on breast cancer incidence is an increased risk, a cross-over to a long-term protection occurs for women of younger maternal age at first birth, which has been referred to as the cross-over effect. Uni-parous women who complete their first pregnancy before age 25 still experience a transient increase in risk, however they are subsequently rewarded with a lifetime risk reduction of $36 \%$ for developing breast cancer [9]. Likewise, increasing parity also confers long term risk reduction, decreasing a women's lifetime risk of developing breast cancer by $7.0 \%$ for each additional birth [10]. Age and parity appear to act synergistically with high parity $[\geq 5]$ and young age $[\leq 20]$ at first birth associated with the greatest ultimate reduction in lifetime breast cancer risk. This protective effect is weakened among multiparous women if their age at first birth is greater than 30 [11]. A family history of breast cancer lowers but does not negate the overall lifetime protective effect with increasing parity [6]. Reduction in lifetime risk for breast cancer with any degree of parity has been variably reported for BRCA1 and BRCA2 mutation carriers [12-14]. (Table 1)

Conversely, advanced maternal age at first birth nearly abrogates the lifetime breast cancer protection as first pregnancy above age 35 results in loss or significant delay in the cross over effect $[15,16]$. These studies note a tail effect of increased risk for up to 50 years post-partum [4, 17], well into the decades of life when breast cancer is

Table 1 Lifetime breast cancer risk associated with age at first pregnancy.

\begin{tabular}{lllll}
\hline \multicolumn{3}{l}{ Risk separated by age (median) } \\
\hline Age & $\begin{array}{l}\text { General } \\
\text { population } \\
{[1,2,18,20]}\end{array}$ & $\begin{array}{l}\text { Family } \\
\text { history } \\
{[5]}\end{array}$ & $\begin{array}{l}\text { BRCA1 } \\
\text { mut carriers } \\
{[13]}\end{array}$ & $\begin{array}{l}\text { BRCA2 } \\
\text { mut carriers } \\
{[13]}\end{array}$ \\
\hline Nullip & $1^{\mathrm{a}}$ & 2.7 & 1.96 & 2.85 \\
$<20$ & 1.06 & 0.53 & $1^{\mathrm{a}}$ & $1^{\mathrm{a}}$ \\
$20-24$ & 1 & 2.1 & 1.08 & 1.74 \\
$25-30$ & 1.11 & 2.1 & 1.08 & 1.48 \\
$>30$ & $1.19-2.19^{\mathrm{c}}$ & 4 & 0.83 & 4.77 \\
\hline
\end{tabular}

${ }^{\mathrm{a}}$ Risk was set to 1 as reference and varies between studies, ${ }^{\mathrm{b}}$ Family member diagnosed before age $50,{ }^{\mathrm{c}}$ Represented as a range since some studies reported $>30$ and others $>35$. 
commonly diagnosed. Thus, for these women, the delayed protective effect of pregnancy against breast cancer will not occur in an average lifetime. Research such as the Shanghai Breast Cancer Study demonstrates how cultural shifts in countries with low incidence of breast cancer and historically young onset of childbearing to more advanced maternal age are also noting an increase in breast cancer incidence [18]. Overall each year of increased maternal age at first birth results in an estimated 3.5\%-5.3\% increase in lifetime relative risk for breast cancer [19, 20]. In terms of lifetime breast cancer risk, the age of 35 years acts as a critical point; prior to this age full-term pregnancy offers women some degree of protection, but after this age fullterm pregnancy is associated with a permanent increase in breast cancer risk [19].

At present, several conclusions can be drawn from the available epidemiologic data on the impact of pregnancy with breast cancer incidence. All women who complete a pregnancy are in a transient period of moderate increased breast cancer risk compared to their nulliparous peers. The degree of increased risk is akin to other routine breast cancer risk factors, such as early menarche and number of first degree relatives affected before age 50 . However, the risks related to pregnancy history are not currently incorporated into clinical tools for assessing a woman's risk for the development of breast cancer. Greater understanding of this transient increase is needed for subsequent adaptation into clinical breast cancer risk assessment. Moreover, attention to this breast cancer risk factor is warranted in the assessment of young women presenting with breast complaints in the post-partum years and consideration of such risk along with the clinical guidelines for evaluation of such complaints is required to avoid false reassurance or delayed diagnosis.

\section{What Underlies the Epidemiologic Data?}

There are several possible and likely intertwined hypotheses as to underlying mechanisms driving the dual effect. The transient increase in breast cancer risk experienced by all parous women appears to be due to an event or events associated with pregnancy. Candidate contributors to the increased incidence include: pregnancy-related hormones such as estrogen, progesterone, and growth hormone that promote previously initiated cells, immune suppressive effects of pregnancy, and the post-partum involution process $[17,21,22]$. Research on the role of pregnancy related hormones has shown that increased exposure to estrogen, progesterone, and insulin like growth factor 1 (IGF-1), that is increased in pregnancy in response to growth hormone, are associated with promotion of breast cancer cell proliferation [17]. Therefore, it is possible that the transient increased risk for breast cancer observed with a recent pregnancy is due to the significant increase in concentrations of these hormones during pregnancy, resulting in high-level exposures and subsequent tumor initiation and/or promotion. Alternatively, we and others have reported on an event inherently related to pregnancy that may contribute to growth and development of breast cancer cells. This event is post-partum/post-lactational involution. Involution mimics aspects of wound healing and immunosuppression, which are both known to be pro-tumorigenic. We hypothesize that the tissue microenvironment of involution, with its associated immune cell influx, activated fibroblasts, extracellular matrix (ECM) deposition, elevated matrix metalloproteinase levels and bioactive matrix fragments resembles a pro-tumorigenic wounding environment, and may be responsible for the increased incidence and/or poor prognosis of breast cancer with recent pregnancy [17, 23]. This Involution Hypothesis is discussed further below.

There are several hypotheses put forth to explain the biological processes responsible for why young women experience the benefit of the cross-over effect significantly more than older first time mothers. First, full term pregnancy induces terminal differentiation of the mammary gland, which is thought to render the gland less susceptible to tumorigenesis [24-26]. Young mothers receive benefit due to the shorter exposure time between puberty and full term pregnancy, the window of peak susceptibility [26, 27]. Conversely, the persistent risk for advanced maternal age is believed to be due to increased exposure time of breast tissue to potential mutagens before the terminal differentiation of the gland by pregnancy. This belief is backed up by evidence that any interval of $>16$ years between menarche and first birth, regardless of the specific ages when those events occurred, results in an increased risk for breast cancer [27]. Thus, in older first time mothers, there is theoretically a greater chance for pre-malignant breast lesions to develop before a completed pregnancy occurs, which would be subsequently promoted either by the pregnancy or an event associated with that pregnancy, such as post-partum gland involution. Second, increasing parity overall reduces lifetime menstrual cycling which may impact lifelong breast cancer risk via reducing exposure to the cycling of hormones associated with both the luteal (progesterone and to a lesser extent estrogen) and follicular/ ovulatory (estradiol) phases of menstruation [21, 22]. Finally, there is recent evidence in rodents suggesting that a decrease in mammary stem cells occurs with early parity [28]. If one accepts the mammary tumor stem cell hypothesis, which proposes that stem cells in the mammary gland are the targets for transformation [29-33], then a global reduction in the number of mammary gland stem cells would be anticipated to reduce a woman's lifetime risk. 
Further research is needed to delineate the mechanisms underpinning the dual effect and cross over effect of pregnancy on breast cancer. Objectives would be to define chemotherapeutics aimed at abrogation of the transient risk and enhancement of the protective effects of pregnancy. Hopeful results of this research would result in a reduction in diagnosis of PABC and young women's breast cancer overall.

\section{Lactation and Breast Cancer Risk: a Prevention Strategy?}

In contrast to the relatively robust body of data outlining the effects of pregnancy on breast cancer incidence, the distinct role that lactation contributes has been harder to isolate. Overall, lactation is attributed with a wide range of relative risk reductions, ranging from $4.3-64 \%$ in 89 reported studies to date $[10,34,35]$. Meta-analyses on these studies revealed multiple benefits, including that a protective effect was conferred by lactation with reductions in relative risk for pre-menopausal breast cancer as high as $64 \%$ [34]. These studies demonstrate that a woman's relative risk can be decreased by $4.3 \%$ for every 12 months of lactation [10], and that any degree of lactation but particularly extended lactation can be protective [35]. However, some of the studies examined in these metaanalyses revealed no correlation between lactation and reduction of a woman's risk for breast cancer [34, 35]. These epidemiologic studies on lactation are complicated, and potentially inconclusive, when viewed en masse due to issues that include inherently varying definitions of lactation, inability to control for potentially important cofounders such as body mass index (BMI), exclusivity of lactation, lifetime level versus per pregnancy exposure, and concomitant medications or medical conditions, to name a few.

In addressing the overlapping epidemiologic effects of pregnancy and lactation, it can be postulated that for women at increased risk for breast cancer due to recent childbirth, post-partum lactation would mitigate this increase. One study of the effect of lactation on the transient increased risk of breast cancer in the 5 year interval from most recent child-birth showed that any duration of lactation conferred reduction against the peak increase in PABC risk [3]. Specifically, within 5 years of parturition, absence of lactation conferred an overall risk of 1.64, while presence of lactation reduced this risk to 1.24. The trend continued but the effect was reduced by 5-10 years postpartum. After 10 years post-partum the effect was lost, indicating that the protective effect of lactation is most noted on the transient post-partum period of increased risk for developing breast cancer and limited to nil on lifetime risk of breast cancer [36]. Women with germline mutations in BRCA1 and BRCA2 do not as clearly benefit from lactation $[12,37]$. One potential confounder of this data is the grouping of BRCA1 and BRCA2 mutation carriers as one, given that independent assessment of BRCA1 mutation carriers demonstrated a $44-50 \%$ reduction in risk for breast cancer observed with lactation duration $>1$ year, a greater risk reduction than observed in some studies of the general population [38, 39].

Several hypotheses could explain the protective effect of lactation on transient and overall breast cancer risk. First, similar to pregnancy, lactation promotes terminal differentiation of mammary epithelial cells, potentially rendering them less susceptible to carcinogenic stimuli [40]. This hypothesis is supported by data indicating that very early age at first breastfeeding, $<20$ years is protective beyond that afforded by maternal age at first pregnancy alone [4042]. Second, length of lactation further decreases a woman's lifetime exposure to cycling hormones over pregnancy alone by further suppression of ovulation. An intriguing aspect to this hypothesis comes from the data on women with BRCA1 mutations, where lengthy lactation conferred large benefit [38]. Given the overwhelming propensity for BRCA1 carriers to have hormone receptor negative tumors, the data suggests that another ovarian axis-driven mechanism besides stimulation of tumor cells accounts for the protection afforded by lactation. The known protection from breast cancer observed in BRCA1 carriers through prophylactic oophorectomy, which results in a 56-60\% decrease for development of breast cancer, supports this possibility [39, 43, 44]. Third, in a recently developed mouse model with a precocious lactogenic phenotype, knock-out of Caveolin 3 renders the mice resistant to mammary tumor formation induced by orthotopic tumor cell implantation into the mammary gland [45, 46]. This study indicates that the lactation environment is tumor protective in rodents. One may also postulate that the prolongation of time between two tumor promoting events, pregnancy and involution, by increased length of lactation lessens the chances of these two events acting synergistically to promote progression of previously initiated cells. Lastly, in the case of longer lactation that may naturally dwindle with maturity of the child, could a gradual decrease in lactational pull invoke a less robust involution program than that induced with abrupt cessation?

In summary, lactation may provide a reduction in a woman's transient risk and lifetime chance for developing pre-menopausal breast cancer, with varying degrees of evidence currently available. Interestingly, it has been reported that the United States has a low proportion, only $50 \%$, of parous women who have ever breast fed [10]. From these data, it is possible to hypothesize that any measure instituted to promote breastfeeding practices could also be considered a potential breast cancer prevention strategy. 


\section{Young Women's Breast Cancer and Pregnancy-Associated Breast Cancer: Two Bad Things that Go Together}

Breast cancer is the leading cause of cancer death in US women age 15-29. In 2005, the US alone was estimated to have 11,110 breast cancer cases identified in women under 40 with a concomitant 1,110 deaths. Statistics from similar countries world-wide show near identical rates of incidence and death in young women due to breast cancer [47] Moreover, despite the recent reduction in total incidence of breast cancer, mostly attributable to women over age 50 [48], the annual incidence in the under 40 age range is not decreasing and the absolute number of affected women herein is increasing $[49,50]$.

Regardless of how one chooses to draw the upper limit of age for young women's breast cancer, this population reflects the dominant child-bearing portion of humanity. In 2005, the US reported nearly 5,000 cases of breast cancer diagnosed during pregnancy, making it the second most common co-diagnosed cancer [51]. However, pregnancyassociated breast cancer is more than cases diagnosed during pregnancy. Emerging epidemiologic and prospective research is providing enhanced insight into this subset of young women's breast cancer, allowing it to progress as an important focus for goals of prevention, therapeutics, and survivorship interventions in the future.

\section{PABC Subset \#1: Outcomes when Breast Cancer is Diagnosed During Pregnancy}

When breast cancer is diagnosed concomitantly with pregnancy and is treated with definitive intent to both satisfactorily offer disease control and maintain the pregnancy, long terms outcomes appear equivalent based on age-matched, stage-matched non-pregnant controls [52, 53]. Guidelines on the acceptable management of breast cancer during pregnancy have been published and longterm outcomes in both the treated mothers and their cotreated offspring are favorable [54]. These observations support the ongoing effort to offer pregnancy preservation in the setting of breast cancer therapy when stage of disease at presentation and desires of the patient and involved parties for the child are compatible.

Identified issues that complicate breast cancer diagnosis during pregnancy include delay in diagnosis and subsequent trend toward later stage, including higher incidence of nodal involvement $[55,56]$. Differences as high as an average delay of 5-7 months and 2.5 fold risk of advanced disease have been reported [55-58]. Likewise, enrichment for negative biologic features that worsen prognosis, including higher grade, lower percentage of hormone- receptor positivity, increased Her 2 neu over-expression, and higher Ki-67 nuclear antigen indices are present [5961]. However, if pregnancy alone is an isolated variable with cases matched by stage, age, and year of diagnosis then the diagnosis of breast cancer during pregnancy is not associated with poorer maternal outcome than non-PABC cases [17, 55, 56, 58, 62-65].

Importantly, while some published studies that included women diagnosed during pregnancy have indicated worse maternal outcomes for PABC, these studies either did not match specifically on the known biologic drivers of metastasis and/or included women who were post-partum but lactating or within 1 year of parturition as cases in the same group as women diagnosed when pregnant [66-68]. A recent prospective French study of 40 PABC cases, where $\mathrm{PABC}$ was defined as breast cancer occurring during pregnancy or 1 year after delivery, noted overall survival rates of $72 \%$ for PABC versus $97 \%$ for age-matched controls (Table 2) [68]. This study provides an excellent detailed review of PABC cases, both those diagnosed during pregnancy versus post-partum compared with age matched controls. Overall, the difference in outcomes between groups (combined as both during pregnancy and post-partum) could be correlated with the pregnant PABC cases being enriched for high grade tumors and both PABC subsets enriched for hormone-receptor poor tumors. Likewise, though the mean gestation age at diagnosis was 22 weeks, only three cases received chemotherapy during pregnancy versus 31 post-partum cases, suggesting that a delay of chemotherapy initiation due to pregnancy may be present, and may confound interpretations. The authors also acknowledge that differences in anti-endocrine therapy were present, and both issues may occlude diseasespecific outcomes against the combined PABC cases [69, 70]. These biologic and therapeutic differences do not permit pregnancy to sort out as an independent poorprognostic factor. Categorizing breast cancer according to current identifiable biologic subgroups based on ER, PR, Her 2 status, and tumor grade remains important for delineation of specific pregnancy effects on cancer outcomes and will hopefully provide rational clinical guidance to the co-management of the breast cancer and pregnancy. A caveat to this approach would be if PABC selects for a specific breast cancer subtype.

When taken in isolation, those cases pregnant at diagnosis in the French study and other larger retrospective reviews faired similarly to reports defining cases as solely pregnant at diagnosis and it appears the post-partum cases drove the worsened outcomes for the overall group [6668]. Hence, we emphasize the distinction of two PABC subgroups with $\mathrm{PABC}$ diagnosed during pregnancy more similar to non-PABC when overall outcomes are considered. The unfortunate delay of diagnosis and poorer 
prognostic disease excellently documented in these reviews of concomitant breast cancer with pregnancy [53, 59], highlights the need for attention to clinical breast exams and thorough evaluation of breast concerns in pregnancy.

\section{PABC Subset \#2: Outcomes when Breast Cancer is Diagnosed in the High-Risk Period After Pregnancy}

Converse to the above data, if one focuses on the reported cases of women who are diagnosed with breast cancer subsequently, but within temporal proximity of a completed pregnancy, increased metastasis and death due to breast cancer can be consistently identified, including across large global cohorts [66-68, 71-74]. This worsened prognosis remains independent when age, tumor stage, tumor biologic features, and even patient-related confounders of alcohol use, BMI, education, socioeconomic status, and race [72] are included. The largest of these series from Norway reports outcomes from 516 pregnant cases and 531 within 6 months post-partum at time of diagnosis from a cohort of 42,511 cancers. The highest percentages of death from cancer observed in this study was among cases within 6 months post-partum at $67 \%$ versus $44 \%$ in pregnant cases, and $31 \%$ in controls [66]. Lactation data was unavailable for the post-partum group.

The effect of worsened prognosis in the post-partum period appears to be time dependent and diminishes as increased time occurs between parturition and breast cancer diagnosis. In two large studies, the time frame of diagnosis $<2$ years after giving birth significantly increased hazard ratios for breast cancer death when compared with parturition $\geq 5$ years prior to diagnosis or nulliparous women $[72,75]$. In one of these studies, diagnosis within 12 months of parturition had the worst survival rate at $38 \%$, whereas cases diagnosed 13 48 months and $>48$ months post-partum had survival rates of $51 \%$ and $60 \%$ compared with age-matched nulliparous women at $65 \%$. Other factors controlled for included age at first birth, parity, and breastfeeding duration, indicting that a recent birth alone may be an adverse prognostic factor among young women diagnosed with breast cancer [75]. Exactly when the effect of a recent birth recedes sufficiently to no longer impact risk of metastasis and death remains undefined. A 2008 study of 4,560 British Women with breast cancer whose last pregnancy was more than 30 years ago had a $35 \%$ reduced risk of dying when compared with women who had a full-term pregnancy in the 15 years prior to diagnosis [76], indicating that the number of deaths complicated by PABC could extend as far as even 15 years after pregnancy. (Table 2)

Clarity of definition among the subsets of PABC is important if we are to discern metastatic potential of breast cancers diagnosed during pregnancy, lactation, or post-
Table 2 Survival statistics for women diagnosed during pregnancy or post-partum.

\begin{tabular}{llll} 
\% Survival & & & \\
\hline Study: & Non-PABC & Pregnant & Post-partum \\
\hline Mathelin et al [68] & $97 \%$ & $72 \%$ & $63 \%$ \\
Dodds et al [79] & $80 \%$ & NA & $6.5-13.6 \%$ \\
Stensheim et al [66] & $69 \%$ & $56 \%$ & $33 \%{ }^{\mathrm{b}}$ \\
Beadle et al [77] & $64.8 \%^{\mathrm{a}}$ & $62.6 \%$ & $64.9 \%$ \\
Rodriguez et al [71] & $66.6 \%^{\mathrm{a}}$ & $\mathrm{NA}$ & $61 \%{ }^{\mathrm{c}}$ \\
Daling et al [72] & $75.6-76.7 \%$ & $\mathrm{NA}$ & $51.8 \%(2$ years $)$ \\
Whiteman et al [75] & $65 \%$ & $\mathrm{NA}$ & $38 \%(<1$ year $)$ \\
\hline
\end{tabular}

${ }^{\text {a }}$ Some cases may have been within 5 years post-partum, thus some cases are actually PABC, ${ }^{\mathrm{b}}$ The authors define lactation period as the period from date of delivery to 6 months post-partum, therefore these cases are considered post-partum, ${ }^{\mathrm{c}}$ This is a mix of reproductive states: $22 \%$ pregnant, $1 \%$ diagnosed at delivery, and $76 \%$ postpartum.

partum. A recent retrospective review of an impressive 668 cases of PABC (pregnant or within 1 year of pregnancy) in women age 35 or younger concluded that no significant differences in distant metastasis or overall survival were found compared with non-PABC. Two reasons for this disparate conclusion may reflect the author's choice of dichotomization between pregnant cases, post-partum cases, and controls; an issue that may also confound other studies $[66,71,77]$. Controls in this study were those cases which did not meet their definition of PABC, however, these controls would meet the definition defined by the majority of epidemiologic studies. We have reported that in women under age 40 at breast cancer diagnosis, $18 \%$ will meet the criteria of being within 2 years and $45 \%$ within 6 years of parturition [78]. If the above cited references on the time frame of post-partum $\mathrm{PABC}$ are taken into consideration, many of the control cases from this recent report would potentially be better categorized as PABC and their inclusion may worsen the risk profile of this control group. A strength of this study is the authors excellent delineation of their study groups, including that $25 / 51$ cases of breast cancer diagnosed during pregnancy had treatment delayed until post-partum. The tumors in these cases were persistent into the post-partum period and may be therefore more similar to cancers diagnosed within months of parturition, which have the worst prognosis of all subgroups of PABC [77]. Potentially transferring cases diagnosed during pregnancy, but untreated until postpartum to the post-partum grouping may alter the risk profile of the post-partum cases. However, and most importantly, these authors definitively report on the success that can be achieved by rationale and aggressive management of these high risk tumors in young mothers [77]. 
Overall, the data on PABC support a varying alteration in risk of death from breast cancer for mothers dependent upon time of diagnosis relative to the pregnancy. We believe this supports the presence of distinct subsets of PABC based on biologic aggressiveness: those diagnosed and treated during pregnancy and those diagnosed or treatment delayed until the post-partum period. Conservatively, control or non-PABC groups may be best defined using nulliparous cases or cases greater than 10 years postpartum to mitigate against the uncertainty of when the effects of PABC become negligible to ensuing breast cancer prognosis.

Likewise, the data demonstrates that PABC is not a rare event or niche of breast cancer, but a significant and deadly subset of the disease that may, in fact, be increasing due to cultural shifts regarding child-bearing choices. The Canadian 2008 study predicted that an extra 1 in 13 women with less than 2 years between delivery and diagnosis will die from their disease compared to women with five or more years between delivery and diagnosis [79]. If we apply
Figure 1 Representative human breast tissue sections across the pregnancy, lactation, involution cycle. Human breast tissue sections collected from agematched nulliparous (Nullip) (a), pregnant (Preg) (b), lactating $(L a c)$ (c), involuting $(I n v)(\mathbf{d})$, or fully regressed $(\operatorname{Reg} r)(\mathbf{e})(>10$ years post-partum) women and stained by $H \& E$ to reveal the complex and distinct morphology inherent to each developmental stage, $200 \times$. Each image depicts the size of a single lobule representative of that developmental stage. Human tissue was acquired through a protocol approved by the Colorado Multi-Institutional Review Board.
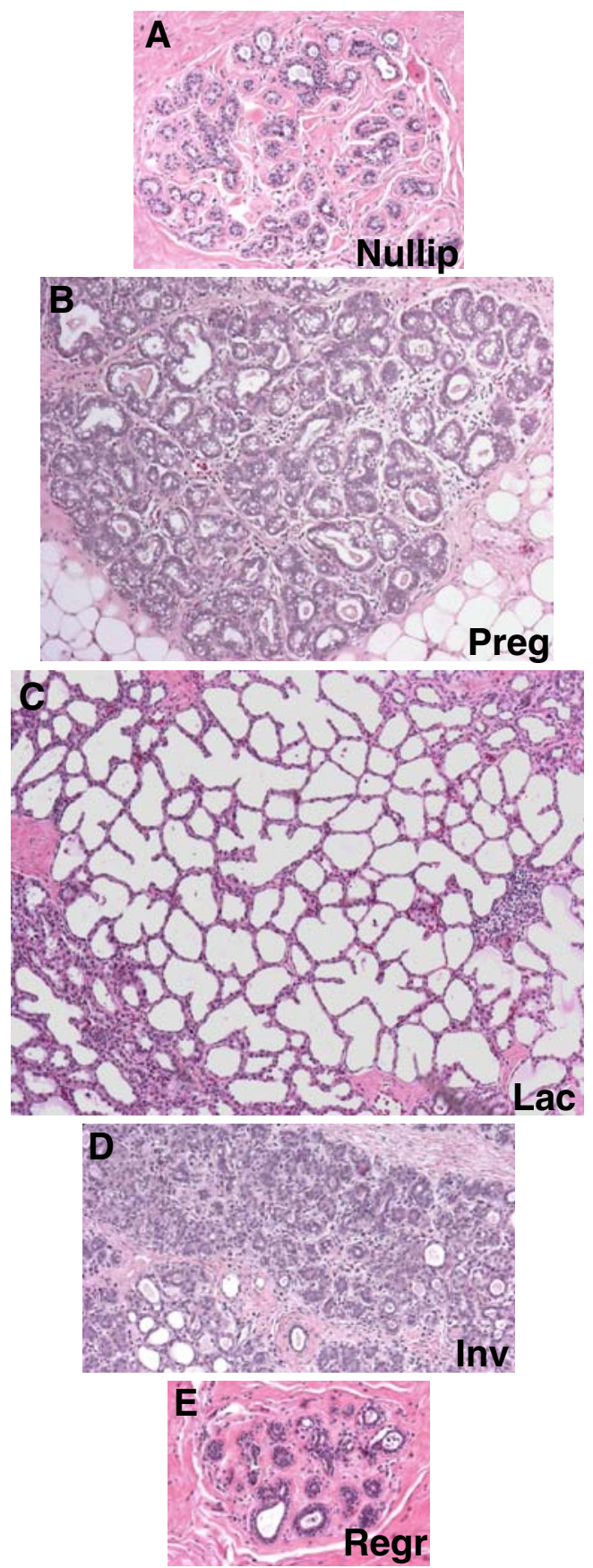
these statistics to US birthrates from 2006, when 4.3 million women experienced live births [80], 25,000 of these women will be diagnosed with invasive breast cancer and 2,000 may die from their disease within 2 years of giving birth.

\section{What Drives the Increase in Metastasis of Post-partum PABC?}

If one accepts the data that breast cancer diagnosed during pregnancy, when stage and biology at diagnosis are taken into account, does not have a pregnancy-specific poorer prognosis, and that cases diagnosed within 5 years of parturition do have a pregnancy-related increased risk, then it can be proposed that an event associated with pregnancy, but not pregnancy itself, may facilitate breast cancer metastasis. We propose that this event is mammary gland involution [17]. Retrospective evidence that supports this hypothesis is found in the association of increased metastatic potential with post-partum breast cancer cases. Involution is a developmentally-regulated process by which the fully differentiated milk-producing breast regresses to a pre-pregnant-like state. Involution occurs at weaning if lactation occurs or post-partum if lactation does not ensue. The scale and rapidity of involution is unique to the mammary gland, involving apoptotic cell death of $50 \%-$ $80 \%$ of the mammary epithelium, and entails a remodeling program that returns the gland to a quiescent state [81, 82]. Accumulating evidence indicates that mammary gland involution utilizes some of the same tissue-remodeling programs that are activated during wound healing and inflammation [83, 84]. These similarities include macrophage cell influx, elevated levels of the immunomodulators TGF beta 1 and 3, and matrix metalloproteinase (MMP)-2, 3 , and -9 , deposition of fibrillar collagen and the onco-fetal protein tenascin, and presence of bioactive proteolytic fragments of the extracellular matrix proteins fibronectin and laminin. These stromal attributes of wound healing/ inflammation have been causally associated with tumor progression [17, 23, 85, 86] and may result in dissemination of tumor cells and metastasis. For example, cells interact with the extracellular matrix protein fibronectin through $\beta_{1}$ integrins. $\beta_{1}$ integrins are required for reepithelialization of a wound [87], and $\beta_{1}$ integrin loss in human breast cancers results in tumor suppression [88]. TGF beta also promotes tumor growth indirectly through activation of the stroma [89], and its upregulation stimulates matrix deposition and proliferation of fibroblasts in the healing wound [85]. Additionally, increased abundance of inflammatory cells is a hallmark of human cancers [90, 91] and pre-clinical models of breast cancer demonstrate that macrophages are required for tumor cell migration, invasion and metastasis [92]. Angiogenesis and lymphangiogenesis, processes that require both MMP activity and deposition of collagen for formation of new vessels, are important steps in both wound healing and tumor progression [93, 94]. Finally, fibronectin is an important component of the early wound healing stroma [85] and has been shown to be a component of the matrices of metastatic tumors as well [95]. These examples highlight only some of the similarities that have been observed between wound healing and tumor progression. Thus, given that a wound healing microenvironment is tumor promotional, and the involution microenvironment is similar to that of wound healing, it can be predicted that involution would promote cancer. Rodent models of involution confirm increased metastasis of human breast cancer cells that have been exposed to the involution micro-environment [96]. More-

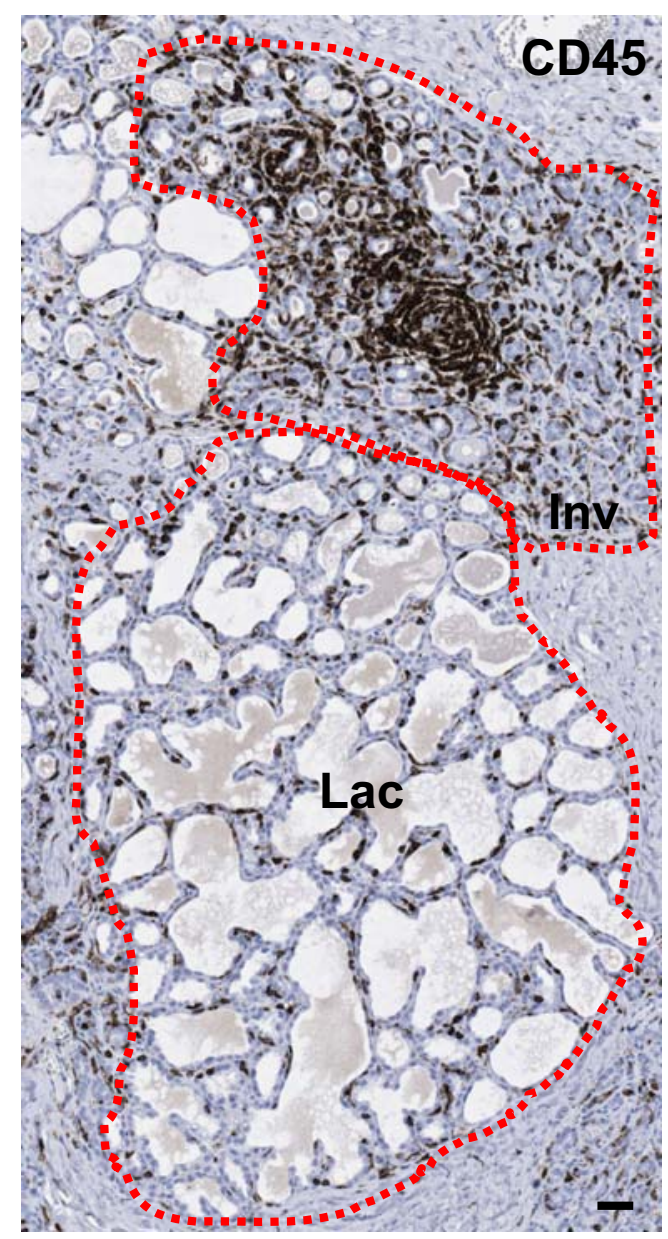

Figure 2 Immune cells are specifically recruited to actively involuting lobules in normal human mammary tissue. Immune cells as detected by IHC for common leukocyte antigen CD45 are stained brown in a breast biopsy from a woman who was actively involuting at the time of the biopsy, which revealed no malignancy (i.e. normal tissue). Both lactating ( $L a c$ ) and involuting (Inv) lobules are present and highlighted with dashed lines. Scale bar indicates $40 \mu \mathrm{m}$. 
over, wound healing and mastitis have been shown to increase breast cancer risk [97, 98] and other types of epithelial cancers are known to result from repetitive wounding and regeneration [85], further implicating the involution microenvironment in tumor promotion.

Evidence that involution utilizes tissue remodeling programs reminiscent of wound healing has been obtained from rodent models, with relevance to women unknown. As evident in Fig. 1, dramatic morphologic changes occur in the human mammary gland with reproductive stage. Elevated proliferation and differentiation during pregnancy and lactation transform the rudimentary branching structure of the nulliparous gland into a florid milk-secreting organ (Fig. 1a-c). During involution, this abundance of proliferative and differentiated growth then transforms to a marked desmoplastic regressing environment, as the gland remodels to a rudimentary structure (Fig. 1d, and data not shown). It is likely that this involution process will utilize a predictable wound healing/inflammatory cascade, such as that described in rodent models. In human tissue, we have found that it is common to observe fully lactational lobules adjacent to involuting lobules. The presence of both lactating and actively involuting lobules in the same tissue specimen permits the investigation of microenvironment changes that are specific to involution, and provides insight into the potential tumor promoting attributes of this period. As evident in Fig. 2, immune cells appear to be specifically recruited to the involuting lobules, as they are much less abundant in the adjacent lactational lobules. This observation indicates that the microenvironment surrounding an involuting lobule is distinct from that of a lactational lobule, and provides compelling evidence that human breast involution utilizes wound healing programs to remodel after pregnancy. If a present malignancy is superimposed on such an inflammatory milieu, then the tumor could be promoted, resulting in increased metastases compared to a tumor that has not been exposed to the involution microenvironment.

\section{What Future for PABC: Prevention of the Collision?}

In conclusion, while parity may reward women who give birth when they are younger than thirty-five with varying degrees of lifetime protection from breast cancer, it is also true that parous women will experience a transient increased period of risk for breast cancer immediately following any childbirth. This transient risk is further increased by older age at first birth, positive family history of breast cancer, and in women with germline mutations in breast cancer susceptibility genes. Of uncertain significance is the protective effect observed with lactation. When tumors are matched for known clinical features, women who are diagnosed with
PABC during pregnancy experience outcomes similar to women diagnosed with non-PABC, indicating that pregnancy per se is not an independent risk factor for breast cancer. Conversely, women who are diagnosed with $\mathrm{PABC}$ in the post-partum period have a poorer prognosis that is independent of known prognostic factors. We believe a major difference between these groups is exposure of the tumor cells to the involution microenvironment, which has attributes of a wound. Women who are diagnosed during pregnancy and treated during pregnancy effectively eliminate the lesion that we propose will be promoted by the involution microenvironment if left in situ. Mechanisms underlying the distinct biology of pregnancy-associated tumors that are promoted by involution are currently being identified in human and rodent mammary tissues in our labs. Our ultimate goal is to target the involution period with intervention strategies that may help eliminate the increased metastatic potential of PABC.

Acknowledgments The authors are grateful to Shou-Ching Tang, MD, PhD, FACP, FRCP (c) and Jeffrey Holt, MD for critical review of the manuscript and to Scott Lucia, MD and Storey Wilson for assistance with the image presented in Fig. 2. This work was supported by grants from the Department of Defense \# BC060531, University of Colorado Cancer Center Seed Grant, Women's Health and Gender Based Disease Grant, and Avon Foundation Breast Cancer Crusade Grant to PS and GB, and American Cancer Society New England Division Postdoctoral Fellowship SpinOdyssey \#PF-08-25701-CSM to TL.

Open Access This article is distributed under the terms of the Creative Commons Attribution Noncommercial License which permits any noncommercial use, distribution, and reproduction in any medium, provided the original author(s) and source are credited.

\section{References}

1. Lambe M, Hsieh C, Trichopoulos D, Ekbom A, Pavia M, Adami HO. Transient increase in the risk of breast cancer after giving birth. $\mathrm{N}$ Engl J Med. 1994;331(1):5-9. doi:10.1056/NEJM199407073310102.

2. Albrektsen G, Heuch I, Hansen S, Kvale G. Breast cancer risk by age at birth, time since birth and time intervals between births: exploring interaction effects. Br J Cancer. 2005;92(1):167-75. doi:10.1038/sj.bjc.6602302.

3. Chie WC, Hsieh C, Newcomb PA, Longnecker MP, Mittendorf R, Greenberg ER, et al. Age at any full-term pregnancy and breast cancer risk. Am J Epidemiol. 2000;151(7):715-22.

4. Liu Q, Wuu J, Lambe M, Hsieh SF, Ekbom A, Hsieh CC. Transient increase in breast cancer risk after giving birth: postpartum period with the highest risk (Sweden). CCC. 2002;13(4):299-305. doi:10.1023/A:1015287208222.

5. Dupont WD, Page DL. Breast cancer risk associated with proliferative disease, age at first birth, and a family history of breast cancer. Am J Epidemiol. 1987;125(5):769-79.

6. Albrektsen G, Heuch I, Thoresen S, Kvale G. Family history of breast cancer and short-term effects of childbirths on breast cancer risk. Int J Cancer. 2006;119(6):1468-74. doi:10.1002/ijc.22003. 
7. Johannsson O, Loman N, Borg A, Olsson H. Pregnancyassociated breast cancer in BRCA1 and BRCA2 germline mutation carriers. Lancet. 1998;352(9137):1359-60. doi:10.1016/S0140-6736(05)60750-7.

8. Cullinane CA, Lubinski J, Neuhausen SL, Ghadirian P, Lynch HT, Isaacs $\mathrm{C}$, et al. Effect of pregnancy as a risk factor for breast cancer in BRCA1/BRCA2 mutation carriers. Int $\mathrm{J}$ Cancer. 2005;117(6):988-91. doi:10.1002/ijc.21273.

9. Lord SJ, Bernstein L, Johnson KA, Malone KE, McDonald JA, Marchbanks PA, et al. Breast cancer risk and hormone receptor status in older women by parity, age of first birth, and breastfeeding: a case-control study. Cancer Epidemiol Biomarkers Prev. 2008;17(7):1723-30. doi:10.1158/1055-9965.EPI-07-2824.

10. Breast cancer and breastfeeding: collaborative reanalysis of individual data from 47 epidemiological studies in 30 countries, including 50302 women with breast cancer and 96973 women without the disease. Lancet. 2002;360(9328):187-95. doi:10.1016/S0140-6736(02)09454-0.

11. Albrektsen G, Heuch I, Tretli S, Kvale G. Breast cancer incidence before age 55 in relation to parity and age at first and last births: a prospective study of one million Norwegian women. Epidemiology. 1994;5(6):604-11. doi:10.1097/00001648-199411000-00008.

12. Lee E, Ma H, McKean-Cowdin R, Van Den Berg D, Bernstein L, Henderson BE, et al. Effect of reproductive factors and oral contraceptives on breast cancer risk in BRCA1/2 mutation carriers and noncarriers: results from a population-based study. Cancer Epidemiol Biomarkers Prev. 2008;17(11):3170-8. doi:10.1158/ 1055-9965.EPI-08-0396.

13. Antoniou AC, Shenton A, Maher ER, Watson E, Woodward E, Lalloo F, et al. Parity and breast cancer risk among BRCA1 and BRCA2 mutation carriers. Breast Cancer Res. 2006;8(6):R72. doi:10.1186/bcr1630.

14. Andrieu N, Goldgar DE, Easton DF, Rookus M, Brohet R, Antoniou AC, et al. Pregnancies, breast-feeding, and breast cancer risk in the International BRCA1/2 Carrier Cohort Study (IBCCS). J Natl Cancer Inst. 2006;98(8):535-44.

15. Rosner B, Colditz GA, Willett WC. Reproductive risk factors in a prospective study of breast cancer: the Nurses' Health Study. Am J Epidemiol. 1994;139(8):819-35.

16. Leon DA, Carpenter LM, Broeders MJ, Gunnarskog J, Murphy MF. Breast cancer in Swedish women before age 50: evidence of a dual effect of completed pregnancy. CCC. 1995;6(4):283-91. doi:10.1007/BF00051403.

17. Schedin P. Pregnancy-associated breast cancer and metastasis. Nat Rev Cancer. 2006;6(4):281-91. doi:10.1038/nrc1839.

18. Gao YT, Shu XO, Dai Q, Potter JD, Brinton LA, Wen W, et al. Association of menstrual and reproductive factors with breast cancer risk: results from the Shanghai Breast Cancer Study. Int J Cancer. 2000;87(2):295-300. doi:10.1002/1097-0215(20000715) 87:2\&lt;295::AID-IJC23\&gt;3.0.CO;2-7.

19. Trichopoulos D, Hsieh CC, MacMahon B, Lin TM, Lowe CR, Mirra AP, et al. Age at any birth and breast cancer risk. Int J Cancer. 1983;31(6):701-4. doi:10.1002/ijc.2910310604.

20. Robertson C, Primic-Zakelj M, Boyle P, Hsieh CC. Effect of parity and age at delivery on breast cancer risk in Slovenian women aged 25-54 years. Int J Cancer. 1997;73(1):1-9. doi:10.1002/(SICI)1097-0215(19970926)73:1\&1t;1::AIDIJC1\&gt;3.0.CO;2-U.

21. Pike MC, Krailo MD, Henderson BE, Casagrande JT, Hoel DG. 'Hormonal' risk factors, 'breast tissue age' and the age-incidence of breast cancer. Nature. 1983;303(5920):767-70. doi:10.1038/ $303767 \mathrm{a} 0$

22. Rossouw JE, Anderson GL, Prentice RL, LaCroix AZ, Kooperberg $\mathrm{C}$, Stefanick ML, et al. Risks and benefits of estrogen plus progestin in healthy postmenopausal women: principal results From the
Women's Health Initiative randomized controlled trial. JAMA. 2002;288(3):321-33. doi:10.1001/jama.288.3.321.

23. Schedin P, O'Brien J, Rudolph M, Stein T, Borges V. Microenvironment of the involuting mammary gland mediates mammary cancer progression. J Mammary Gland Biol Neoplasia. 2007;12 (1):71-82. doi:10.1007/s10911-007-9039-3.

24. Ferguson DJ, Anderson TJ. A morphological study of the changes which occur during pregnancy in the human breast. Virchows Arch A Pathol Anat Histopathol. 1983;401(2):163-75. doi:10.1007/ BF00692642.

25. Russo J, Calaf G, Roi L, Russo IH. Influence of age and gland topography on cell kinetics of normal human breast tissue. J Natl Cancer Inst. 1987;78(3):413-8.

26. Russo J, Tay LK, Russo IH. Differentiation of the mammary gland and susceptibility to carcinogenesis. Breast Cancer Res Treat. 1982;2(1):5-73. doi:10.1007/BF01805718.

27. Li CI, Malone KE, Daling JR, Potter JD, Bernstein L, Marchbanks PA, et al. Timing of menarche and first full-term birth in relation to breast cancer risk. Am J Epidemiol. 2008;167(2):230-9. doi:10.1093/aje/kwm271.

28. Siwko SK, Dong J, Lewis MT, Liu H, Hilsenbeck SG, Li Y. Evidence that an early pregnancy causes a persistent decrease in the number of functional mammary epithelial stem cellsimplications for pregnancy-induced protection against breast cancer. Stem Cells. 2008;26(12):3205-9. doi:10.1634/stem cells.2008-0103.

29. Chepko G, Smith GH. Mammary epithelial stem cells: our current understanding. J Mammary Gland Biol Neoplasia. 1999;4(1):3552. doi:10.1023/A:1018752519356.

30. Smith GH, Chepko G. Mammary epithelial stem cells. Microsc Res Tech. 2001;52(2):190-203. doi:10.1002/1097-0029 (20010115) 52:2\&lt;190::AID-JEMT1005\&gt;3.0.CO;2-O.

31. Wicha MS. Identification of murine mammary stem cells: implications for studies of mammary development and carcinogenesis. Breast Cancer Res. 2006;8(5):109.

32. Wicha MS, Liu S, Dontu G. Cancer stem cells: an old idea-a paradigm shift. Cancer Res. 2006;66(4):1883-90. doi:10.1158/ 0008-5472.CAN-05-3153. discussion 1895-6.

33. Polyak K, Hahn WC. Roots and stems: stem cells in cancer. Nat Med. 2006;12(3):296-300. doi:10.1038/nm1379.

34. Lipworth L, Bailey LR, Trichopoulos D. History of breast-feeding in relation to breast cancer risk: a review of the epidemiologic literature. J Natl Cancer Inst. 2000;92(4):302-12. doi:10.1093/ jnci/92.4.302.

35. Yang L, Jacobsen KH. A systematic review of the association between breastfeeding and breast cancer. J Womens Health (Larchmt). 2008;17(10):1635-45. doi:10.1089/jwh.2008.0917.

36. Peterson NB, Huang Y, Newcomb PA, Titus-Ernstoff L, Trentham-Dietz A, Anic G, et al. Childbearing recency and modifiers of premenopausal breast cancer risk. Cancer Epidemiol Biomarkers Prev. 2008;17(11):3284-7. doi:10.1158/1055-9965. EPI-08-0577.

37. Tryggvadottir L, Olafsdottir EJ, Gudlaugsdottir S, Thorlacius S, Jonasson JG, Tulinius $\mathrm{H}$, et al. BRCA2 mutation carriers, reproductive factors and breast cancer risk. Breast Cancer Res. 2003;5(5):R121-8. doi:10.1186/bcr619.

38. Jernstrom H, Lubinski J, Lynch HT, Ghadirian P, Neuhausen S, Isaacs $\mathrm{C}$, et al. Breast-feeding and the risk of breast cancer in BRCA1 and BRCA2 mutation carriers. J Natl Cancer Inst. 2004;96(14):1094-8.

39. Gronwald J, Byrski T, Huzarski T, Cybulski C, Sun P, Tulman A, et al. Influence of selected lifestyle factors on breast and ovarian cancer risk in BRCA1 mutation carriers from Poland. Breast Cancer Res Treat. 2006;95(2):105-9. doi:10.1007/s10549-0059051-5. 
40. Enger SM, Ross RK, Paganini-Hill A, Bernstein L. Breastfeeding experience and breast cancer risk among postmenopausal women. Cancer Epidemiol Biomarkers Prev. 1998;7(5):365-9.

41. Shema L, Ore L, Ben-Shachar M, Haj M, Linn S. The association between breastfeeding and breast cancer occurrence among Israeli Jewish women: a case control study. J Cancer Res Clin Oncol. 2007;133(8):539-46. doi:10.1007/s00432-007-0199-8.

42. Newcomb PA, Storer BE, Longnecker MP, Mittendorf R, Greenberg ER, Clapp RW, et al. Lactation and a reduced risk of premenopausal breast cancer. N Engl J Med. 1994;330(2):81-7. doi:10.1056/ NEJM199401133300201.

43. Rebbeck TR, Kauff ND, Domchek SM. Meta-analysis of risk reduction estimates associated with risk-reducing salpingooophorectomy in BRCA1 or BRCA2 mutation carriers. J Natl Cancer Inst. 2009;101(2):80-7. doi:10.1093/jnci/djn442.

44. Eisen A, Lubinski J, Klijn J, Moller P, Lynch HT, Offit K, et al. Breast cancer risk following bilateral oophorectomy in BRCA1 and BRCA2 mutation carriers: an international case-control study. J Clin Oncol. 2005;23(30):7491-6. doi:10.1200/JCO.2004.00.7138.

45. Sotgia F, Casimiro MC, Bonuccelli G, Liu M, Whitaker-Menezes D, $\mathrm{Er} \mathrm{O}$, et al. Loss of caveolin-3 induces a lactogenic microenvironment that is protective against mammary tumor formation. Am J Pathol. 2009;174(2):613-29. doi:10.2353/ajpath.2009.080653.

46. Sotgia F, Del Galdo F, Casimiro MC, Bonuccelli G, Mercier I, Whitaker-Menezes D, et al. Caveolin-1-/- null mammary stromal fibroblasts share characteristics with human breast cancerassociated fibroblasts. Am J Pathol. 2009;174(3):746-61. doi:10.2353/ajpath.2009.080658.

47. Cancer Mondial In.

48. SEER. SEER Cancer Statistics Review 1975-2005. In; 2005.

49. Bleyer A, Viny A, Barr R. Cancer in 15- to 29-year-olds by primary site. Oncologist. 2006;11(6):590-601. doi:10.1634/theoncologist.116-590.

50. Tarone RE. Breast cancer trends among young women in the United States. Epidemiology. 2006;17(5):588-90. doi:10.1097/01. ede.0000229195.98786.ee.

51. Pereg D, Koren G, Lishner M. Cancer in pregnancy: gaps, challenges and solutions. Cancer Treat Rev. 2008;34(4):302-12. doi:10.1016/j.ctrv.2008.01.002.

52. Garcia-Manero M, Royo MP, Espinos J, Pina L, Alcazar JL, Lopez G. Pregnancy associated breast cancer. Eur J Surg Oncol. 2009;35(2):215-8. doi:10.1016/j.ejso.2008.04.010.

53. Keleher AJ, Theriault RL, Gwyn KM, Hunt KK, Stelling CB, Singletary SE, et al. Multidisciplinary management of breast cancer concurrent with pregnancy. J Am Coll Surg. 2002;194 (1):54-64. doi:10.1016/S1072-7515(01)01105-X.

54. Carlson RW, Edge SB, Theriault RL. NCCN: Breast cancer. Cancer Control. 2001;8 Suppl 2(6):54-61.

55. Bonnier P, Romain S, Dilhuydy JM, Bonichon F, Julien JP, Charpin $\mathrm{C}$, et al. Influence of pregnancy on the outcome of breast cancer: a case-control study. Societe Francaise de Senologie et de Pathologie Mammaire Study Group. Int J Cancer. 1997;72 (5):720-7. doi:10.1002/(SICI)1097-0215(19970904)72:5<720:: AID-IJC3>3.0.CO;2-U.

56. Guinee VF, Olsson H, Moller T, Hess KR, Taylor SH, Fahey T, et al. Effect of pregnancy on prognosis for young women with breast cancer. Lancet. 1994;343(8913):1587-9. doi:10.1016/S0140-6736 (94)93054-6.

57. Petrek JA, Dukoff R, Rogatko A. Prognosis of pregnancy-associated breast cancer. Cancer. 1991;67(4):869-72. doi:10.1002/1097-0142 (19910215) 67:4\&1t;869::AID-CNCR2820670402\&gt;3.0.CO;2-Q.

58. Nugent $\mathrm{P}, \mathrm{O}^{\prime}$ Connell TX. Breast cancer and pregnancy. Arch Surg. 1985;120(11):1221-4.

59. Middleton LP, Amin M, Gwyn K, Theriault R, Sahin A. Breast carcinoma in pregnant women: assessment of clinicopathologic and immunohistochemical features. Cancer. 2003;98(5):1055-60. doi:10.1002/cncr.11614.

60. Gentilini O, Masullo M, Rotmensz N, Peccatori F, Mazzarol G, Smeets A, et al. Breast cancer diagnosed during pregnancy and lactation: biological features and treatment options. Eur J Surg Oncol. 2005;31(3):232-6. doi:10.1016/j.ejso.2004.11.012.

61. Reed W, Hannisdal E, Skovlund E, Thoresen S, Lilleng P, Nesland JM. Pregnancy and breast cancer: a population-based study. Virchows Arch. 2003;443(1):44-50. doi:10.1007/s00428003-0817-z.

62. Zemlickis D, Lishner M, Degendorfer P, Panzarella T, Burke B, Sutcliffe SB, et al. Maternal and fetal outcome after breast cancer in pregnancy. Am J Obstet Gynecol. 1992;166(3):781-7.

63. Ezzat A, Raja MA, Berry J, Zwaan FE, Jamshed A, Rhydderch D, et al. Impact of pregnancy on non-metastatic breast cancer: a case control study. Clin Oncol (R Coll Radiol). 1996;8(6):367-70. doi:10.1016/S0936-6555(96)80081-1.

64. Ribeiro G, Jones DA, Jones M. Carcinoma of the breast associated with pregnancy. Br J Surg. 1986;73(8):607-9. doi:10.1002/ bjs. 1800730805.

65. Petrek JA. Breast cancer during pregnancy. Cancer. 1994;74 Suppl(1):518-27.

66. Stensheim H, Moller B, van Dijk T, Fossa SD. Cause-specific survival for women diagnosed with cancer during pregnancy or lactation: a registry-based cohort study. J Clin Oncol. 2009;27 (1):45-51. doi:10.1200/JCO.2008.17.4110.

67. Lethaby AE, O'Neill MA, Mason BH, Holdaway IM, Harvey VJ. Overall survival from breast cancer in women pregnant or lactating at or after diagnosis. Auckland Breast Cancer Study Group. Int J Cancer. 1996;67(6):751-5. doi:10.1002/(SICI)10970215(19960917)67:6<751::AID-IJC1>3.0.CO;2-Q.

68. Mathelin C, Annane K, Treisser A, Chenard MP, Tomasetto C, Bellocq JP, et al. Pregnancy and post-partum breast cancer: a prospective study. Anticancer Res. 2008;28(4C):2447-52.

69. Nettleton J, Long J, Kuban D, Wu R, Shaefffer J, El-Mahdi A. Breast cancer during pregnancy: quantifying the risk of treatment delay. Obstet Gynecol. 1996;87(3):414-8. doi:10.1016/0029-7844 (95)00470-X.

70. Buzdar AU, Smith TL, Powell KC, Blumenschein GR, Gehan EA. Effect of timing of initiation of adjuvant chemotherapy on disease-free survival in breast cancer. Breast Cancer Res Treat. 1982;2(2):163-9. doi:10.1007/BF01806452.

71. Rodriguez AO, Chew H, Cress R, Xing G, McElvy S, Danielsen $\mathrm{B}$, et al. Evidence of poorer survival in pregnancy-associated breast cancer. Obstet Gynecol. 2008;112(1):71-8.

72. Daling JR, Malone KE, Doody DR, Anderson BO, Porter PL. The relation of reproductive factors to mortality from breast cancer. Cancer Epidemiol Biomarkers Prev. 2002;11(3):235-41.

73. Bladstrom A, Anderson H, Olsson H. Worse survival in breast cancer among women with recent childbirth: results from a Swedish population-based register study. Clin Breast Cancer. 2003;4(4):280-5. doi:10.3816/CBC.2003.n.033.

74. Whitman GJ, Sheppard DG, Phelps MJ, Gonzales BN. Breast cancer staging. Semin Roentgenol. 2006;41(2):91-104. doi:10.1053/j.ro.2006.03.003.

75. Whiteman MK, Hillis SD, Curtis KM, McDonald JA, Wingo PA, Marchbanks PA. Reproductive history and mortality after breast cancer diagnosis. Obstet Gynecol. 2004;104(1):146-54.

76. Barnett GC, Shah M, Redman K, Easton DF, Ponder BA, Pharoah PD. Risk factors for the incidence of breast cancer: do they affect survival from the disease? J Clin Oncol. 2008;26(20):3310-6. doi:10.1200/JCO.2006.10.3168.

77. Beadle BM, Woodward WA, Middleton LP, Tereffe W, Strom EA, Litton JK, et al. The impact of pregnancy on breast cancer outcomes in women $</=35$ years. Cancer. 2009. 
78. Borges V, Albrektsen G, Schedin P. Identification of pregnancyassociated breast cancer (PABC) for investigation of the role of mammary gland involution in promoting metastasis in a Norwegian cohort of breast cancer cases. In: Era of Hope. Baltimore, MD; 2008.

79. Dodds L, Fell DB, Joseph KS, Dewar R, Scott H, Platt R, et al. Relationship of time since childbirth and other pregnancy factors to premenopausal breast cancer prognosis. Obstet Gynecol. 2008;111(5):1167-73.

80. Services UDoHaH. Live Births. In; 2008.

81. Dickson SR, Warburton MJ. Enhanced synthesis of gelatinase and stromelysin by myoepithelial cells during involution of the rat mammary gland. J Histochem Cytochem. 1992;40(5):697-703.

82. Schwertfeger KL, Richert MM, Anderson SM. Mammary gland involution is delayed by activated Akt in transgenic mice. Mol Endocrinol. 2001;15(6):867-81. doi:10.1210/me.15.6.867.

83. Clarkson RW, Wayland MT, Lee J, Freeman T, Watson CJ. Gene expression profiling of mammary gland development reveals putative roles for death receptors and immune mediators in postlactational regression. Breast Cancer Res. 2004;6(2):R92-109. doi:10.1186/bcr754.

84. Stein T, Morris JS, Davies CR, Weber-Hall SJ, Duffy MA, Heath $\mathrm{VJ}$, et al. Involution of the mouse mammary gland is associated with an immune cascade and an acute-phase response, involving LBP, CD14 and STAT3. Breast Cancer Res. 2004;6(2):R75-91. doi: $10.1186 /$ bcr753.

85. Schafer M, Werner S. Cancer as an overhealing wound: an old hypothesis revisited. Nat Rev Mol Cell Biol. 2008;9(8):628-38. doi: $10.1038 / \mathrm{nrm} 2455$.

86. Coussens LM, Werb Z. Inflammation and cancer. Nature. 2002;420(6917):860-7. doi:10.1038/nature01322.

87. Grose R, Hutter C, Bloch W, Thorey I, Watt FM, Fassler R, et al. A crucial role of beta 1 integrins for keratinocyte migration in vitro and during cutaneous wound repair. Development. 2002;129(9):2303-15.

88. White DE, Kurpios NA, Zuo D, Hassell JA, Blaess S, Mueller U, et al. Targeted disruption of betal-integrin in a transgenic mouse model of human breast cancer reveals an essential role in mammary tumor induction. Cancer Cell. 2004;6(2):159-70. doi:10.1016/j.ccr.2004.06.025.

89. Wakefield LM, Roberts AB. TGF-beta signaling: positive and negative effects on tumorigenesis. Curr Opin Genet Dev. 2002;12 (1):22-9. doi:10.1016/S0959-437X(01)00259-3.

90. de Visser KE, Eichten A, Coussens LM. Paradoxical roles of the immune system during cancer development. Nat Rev Cancer. 2006;6(1):24-37. doi:10.1038/nrc1782.

91. Balkwill F, Charles KA, Mantovani A. Smoldering and polarized inflammation in the initiation and promotion of malignant disease. Cancer Cell. 2005;7(3):211-7. doi:10.1016/j.ccr.2005.02.013.

92. Condeelis J, Pollard JW. Macrophages: obligate partners for tumor cell migration, invasion, and metastasis. Cell. 2006;124(2):263-6. doi:10.1016/j.cell.2006.01.007.

93. Ferrara N, Kerbel RS. Angiogenesis as a therapeutic target. Nature. 2005;438(7070):967-74. doi:10.1038/nature04483.

94. Saharinen P, Tammela T, Karkkainen MJ, Alitalo K. Lymphatic vasculature: development, molecular regulation and role in tumor metastasis and inflammation. Trends Immunol. 2004;25(7):38795. doi:10.1016/j.it.2004.05.003.

95. Dvorak HF. Tumors: wounds that do not heal. Similarities between tumor stroma generation and wound healing. N Engl J Med. 1986;315(26):1650-9.

96. McDaniel SM, Rumer KK, Biroc SL, Metz RP, Singh M, Porter W, Schedin P. Remodeling of the mammary microenvironment after lactation promotes breast tumor cell metastasis. Am J Pathol. 2006;168(2). doi:10.2353/ajpath.2006.050677.

97. Jacobs TW, Byrne C, Colditz G, Connolly JL, Schnitt SJ. Radial scars in benign breast-biopsy specimens and the risk of breast cancer. N Engl J Med. 1999;340(6):430-6. doi:10.1056/ NEJM199902113400604.

98. Peters F, Kiesslich A, Pahnke V. Coincidence of nonpuerperal mastitis and noninflammatory breast cancer. Eur J Obstet Gynecol Reprod Biol. 2002;105(1):59-63. doi:10.1016/S0301-2115(02)00109-4. 